\title{
Mother-Daughter Relationship and Daughter's Body Image
}

\author{
Vered Shenaar-Golan, Ofra Walter \\ Tel-Hai Academic College, Kiryat Shmona, Israel \\ Email: ofrawa@telhai.ac.il
}

Received 24 March 2015; accepted 7 May 2015; published 13 May 2015

Copyright (C) 2015 by authors and Scientific Research Publishing Inc.

This work is licensed under the Creative Commons Attribution International License (CC BY). http://creativecommons.org/licenses/by/4.0/

c. (i) Open Access

\begin{abstract}
The adolescent years are characterized by emotional upheaval and hormonal and physiological changes that often create tension and conflicts between girls and their parents. This research study is based on an analysis of the mother-adolescent daughter relationship, with 46 motherdaughter dyads. This research assessed the effect of the daughter's body image (independent variable) and her view of her own mother-daughter relationship (independent variable) on her sense of wellbeing (dependent variable). This study used four questionnaires to evaluate the dyadic model: the Modified Gray's Questionnaire (Body Image), the Leisure Time Exercise Questionnaire (LTEQ), the Mental Health Inventory (MHI) for measurement of the subjective sense of wellbeing, and the Relationship with Mother Questionnaire. Study findings show the importance of the adolescent girl's positive body image on her sense of wellbeing, as well as the centrality of the mother-daughter relationship in the daughter's body image and wellbeing.
\end{abstract}

\section{Keywords}

Body Image, Subjective Wellbeing, Adolescent, Mother-Daughter Relationship

\section{Introduction}

We live in a society that promotes certain standards of beauty, and children are exposed to these from an early age. These standards impact upon our social status and our emotional state [1]. Deviation from modern society's accepted beauty ideal can lead to a decline in self-worth, negative body image, and damage to a person's general wellbeing [2].

Prominent among body image concerns is dissatisfaction with weight and body shape, especially among adolescent girls. Body image emerges as a significant factor affecting health and wellbeing during this developmental phase, as youth begin to focus more on their physical appearance. How adolescents formulate and define 
their body image ideals and subsequent self-comparisons is strongly influenced by personal, cultural factors [3] [4], physiological changes [5]-[7], and by the parent-child relationship.

The mother-daughter relationship plays an extremely important role in creating an adolescent girl's perception of herself and her body [8]-[10].

This quantitative study investigated the relationship between mothers and their adolescent daughters and the relationship's effect on the development of the daughter's body image. Although much has been written about body image and teenage girls, fewer studies have focused on identifying factors that moderate the relationship between body image and psychological functioning, such as the nature of the mother-daughter relationship and how the two perceive the daughter's body image. This study examined this perception from two points of view: the daughter's view of herself and her mother's perception of the way her daughter sees her own body. It also examined the relationship between the girl's body image and her perception of her own wellbeing. We asked 46 mother-daughter dyads to respond to questions about their relationship, the level of satisfaction they feel in their lives, and both the mother's and the daughter's view of the daughter's body image.

\section{Research Literature}

\subsection{Adolescent Girls' Body Image}

Body image is defined as the subjective picture of the shape and size of one's body and the emotions that one relates to one's body parts and the body as a whole [11]-[14]. Body image is formed by cognitive evaluation and comparisons to others, often done unconsciously, involving neurological, emotional, and social elements [15][17] and influenced by socio-cultural norms [1].

Normally, one's body image is formed over a gradual and lengthy process beginning at birth and shaped by the body's contact with its environment, the attitudes of parents and significant adults, and then peers. Body image can also change, however, as a result of crises [13] [14] [18].

Body image has an important but problematic role in the daily functioning of adolescent girls. They are greatly influenced by the cultural perception of the ideal body [19] given the strong emphasis placed on beauty and the outward appearance of the female body [19]-[22] in the media, in education, and in familial and social surroundings [19]. Bodily changes in adolescents can greatly influence social standing, self-confidence, and family relationships [23]. These changes take place in build, outward appearance, height, weight, proportions, and posture [24] [25], forcing adolescents to cope with physiological alterations that hamper their ability to form a positive body image. Forming a positive body image is one of their great challenges [26], since boys and girls constantly cope with the social demand for thinness and the ideal figure. Physical development in adolescents also results in a tendency to exaggerated interest in physical attractiveness [6]. Outward appearance and body build are of extreme importance at this age; in fact, many adolescents hold a stereotypical perception that success in life depends upon outward appearance [25]. The Body Mass Index $\left(B M I=\mathrm{kg} / \mathrm{M}^{2}\right)$ used to measure adiposity has been employed by researchers to predict the effect of body weight on body image. While one recent study found that BMI is an inaccurate predictor for body image among adolescent boys and girls [1], previous research [27]-[29] has demonstrated that BMI is a consistent predictor of girls' negative body image and for boys as well [30].

Although body image has been found to influence psychological wellbeing indifferent phases of life, this relationship is strongest during adolescence [29] [31]-[33]. At least 50\% of adolescent girls in the United States are unhappy with their appearance [32] and similar findings have been reported in Australia [34] [35]. Subjective ratings of body image remain relatively stable across the early teenage years, but become increasingly negative around age 15 - 18 years because of pubertal changes (e.g., widening of the hips). Although much has been written about the prevalence of poor body image in teenagers, particularly teenage girls, fewer studies have focused on identifying factors that moderate the relationship between body image and psychological functioning such as the nature of the mother-daughter relationship and how the two perceive the daughter's body image.

\subsection{The Mother-Daughter Relationship during Adolescence and the Development and Formation of Body Image}

The mother-daughter relationship is one of the most intricate relationships between two people, and during adolescence it can be complex and multi-faceted [36]. There are several theories and viewpoints relating to the 
mother-daughter relationship that affect the development of adolescent girls' body image. Psychoanalysts have maintained that a daughter's greatest object of love is her mother; every stage of a girl's development is influenced by her attachment to her mother [37]. Interpersonal relationships have been viewed by investigators as a primary means through which people develop identity and positive self-image/body image throughout the lifespan [38] [39]. Some researchers have discussed the concept of interpersonal relationships from the perspective of attachment relationships, beginning in infancy with attachment to primary caregivers [40] [41]. A sense of security with an attachment figure instills a positive self-image, whereby a person feels good about him/herself in a variety of adjustment areas including body image, vocational/educational goals, and social relationships [42] [43].

Fisher [44] claimed that the mother-daughter relationship is of utmost importance to the female's self-definition; therefore, a positive relationship is necessary for the healthy development of the daughter [45]. Studies have also shown that the mother-daughter relationship greatly influences the formation of the adolescent girl's perception of herself and her body [8]. It has been shown that a mother's conduct, together with her relationship with her daughter, can directly and indirectly impact her daughter's eating habits and body image [46]. Specifically, unclear boundaries within a family and a complex and thorny relationship between mother and daughter can add significantly to a negative body image [10].

Studies have shown that parents who worry about their weight and their looks serve as a model for imitation among their children, who tend to follow patterns of body image concern [10] [47] [48]. Though they may be unaware of doing so, some parents pressure their children regarding all that relates to eating and body weight, generating feelings of dissatisfaction with their bodies, and sometimes resulting in an eating disorder [47]. Hall and Brown [49] found that mothers of daughters with anorexia nervosa showed a higher level of dissatisfaction with their own bodies and concern for their weight than did mothers of non-anorexic daughters. Similarly, Steiger and colleagues [48] found a close connection between mothers and daughters regarding their weight concerns. Their study findings indicated that the daughter's body image is positively connected to the mother's subjective sense of wellbeing, and that both increase proportionally to one another. It seems that in a relationship where the mother is not concerned with body weight and body image of the daughter, the daughter is free from anxiety regarding weight and image and more likely to be satisfied with her life. However, Attie and BrooksGunn [50] found that mothers with compulsive eating disorder and negative body image do not necessarily have daughters concerned about weight and body image.

Documentation of the psycho-social state among young girls in several research studies found that adolescent girls reach a crossroads with one road leading to a decline in their self-value, body image, and even in their academic achievement. This is the time when girls are about to enter the adult world, and many researchers feel that it is imperative to explore this crossroads in the context of the mother-daughter relationship [51]. Results have emphasized the significance of the mother-adolescent relationship and the importance of targeting counseling interventions at improving parenting practices and helping adolescents to regulate negative affect as a means of preventing the development of maladaptive eating [9].

Interpersonal relationships are also a contributor to wellbeing [38] [39] [41] [43] [52]-[55]. Intense and longlasting bonds of affection have been found, in particular, to have positive effects on self-esteem, body image [56], and emotional adjustment [42] [57]. Greenberg et al., [41] examined how attachment is related to wellbeing during adolescence and found that parental attachment had a stronger relationship to wellbeing than peer attachment. According to Greenberg et al. [41], attachment to parents depends not on proximity but on emotional ties. Armsden and Greenberg [58], through the development of the Inventory of Parent and Peer Attachment, determined that strong parent-adolescent attachment allows adolescents to independently seek out and thrive in new situations.

\subsection{Adolescent Wellbeing}

At the center of the study of wellbeing lies the examination of the individual's subjective feelings about the quality of his/her own life-subjective wellbeing. Subjective wellbeing (SWB) is defined as "an umbrella term for different valuations that people make regarding their lives, the events happening to them, their body and minds, and circumstances in which they live" [59]. SWB has a multi-dimensional structure; it comprises two distinctive components [60]: a cognitive component, related to appraisals of life satisfaction, and an affective component, which refers to both the presence of high levels of positive affect and low levels of negative emo- 
tional experiences [59] [61]-[63]. The affective component is a hedonic evaluation guided by emotions and feelings, while the cognitive component is an information-based appraisal of one's life satisfaction, wherein people judge the extent to which their lives have been measured by their experiences [59].

Studies that investigate SWB evaluate the combination of both the cognitive and affective components [64]. These experiences focus on the person's feelings and resources, such as coping strategies [65]. An individual's sense of wellbeing influences the way in which he/she copes with stress in difficult life situations and with developmental challenges such as adolescence. Studies have shown that high levels of positive wellbeing serve as a helpful coping factor, since a positive sense of wellbeing stimulates a person's social skills, curiosity, and vitality, prompting him/her to make decisions and even stirring his/her creative thinking. People with positive SWB respond quickly to negative events and cope with them better than those with negative SWB, who have difficulty coping with stressful life events [66].

Research studies based on a hedonistic approach to the topic of individual wellbeing among youths usually focus on examining the adolescent's feelings of satisfaction, showing that wellbeing at this age is connected to a variety of personal characteristics: a sense of capability and externalization traits, environmental characteristics such as the extent of parental support, age-related factors affecting the nature of the child-parent relationship, how they perceive themselves, and how they think others see them [67].

The findings pertaining to the contribution of a secure parental relationship, in the context of a sense of personal wellbeing among adolescents, varied in different studies. One study identified three dimensions through which the adolescents defined their wellbeing: being valuable, capable, and confident. The study respondents felt that these features could be related to interpersonal relationships, such as their relationship with their parents. They also cited other elements contributing to wellbeing such as fun activities, good health, the ability to cope with stress, eating, and physical activity [68] [69]. The current research examined adolescent girls' SWB and its connection to their body image from the perspective of both members of mother-daughter dyads, as well as the influence of the quality of their relationship on the daughters' SWB.

\section{Method}

The study examined the connection between body image (independent variable) and subjective sense of wellbeing (dependent variable) in adolescent girls, and the perceived correlation between them, from two points of view: the daughter's view of herself and her mother's perception of the way her daughter sees her own body. Subjective sense of wellbeing was examined for both mother and daughter, as was the influence of the quality of their relationship. In addition, two objective variables were evaluated: participation in physical activity and BMI.

\subsection{Participants}

Forty-six dyads, mothers and adolescent daughters in Israel, participated in the research, resulting in a total of 92 research participants. The mothers' mean age was 41.1, mean height 164.8 and weight $64.3 \mathrm{~kg}$, and the mean BMI was 23.35 , indicating normal weight and body mass. Family status indicated that $82.6 \%$ were married or lived with a partner, $4.3 \%$ were single (and raise their children alone) and $10.9 \%$ were divorced, while $2.2 \%$ did not fall into a category offered. Among the mothers, $69.6 \%$ had an academic education, $19.6 \%$ had another type of education beyond secondary school, $8.7 \%$ had a high school education and $2.2 \%$ had an elementary education. The daughters ranged in age from 12 - 17. Their mean age was 14.82 years, mean weight $52.4 \mathrm{~kg}$ and mean height $159.4 \mathrm{~cm}$. Their mean BMI was 20.62, indicating normal weight and body mass.

\subsection{Research Tools}

Three questionnaires were utilized in the research study:

1) Leisure Time Exercise Questionnaire (LTEQ) [70] (quantitative variable): This is a self-reporting questionnaire asking respondents to describe their mean level of weekly physical activity (more than 15 minutes) by noting the number of times per week they engage in physical activity. Among adults, the questionnaire was found to have a high test-retest reliability $(r=0.74)$ [70]. The LTEQ provides information regarding the factor of physical activity, which may influence body image. In the current research study, the questionnaire was found to be of average internal reliability for the mothers $(\alpha=0.64)$ and for the daughters $(\alpha=0.60)$. 
2) Body Mass Index (BMI $\left.=\mathrm{kg} / \mathrm{M}^{2}\right)$ is used to measure adiposity [71]. Height was measured to the nearest millimeter using stadiometers and weight was measured with digital scales. BMI of less than 18.5 is considered underweight, 18.5 - 24.9 is considered normal and optimal, and over 25 is considered overweight [72].

3) Modified Gray's Questionnaire-This questionnaire examines the independent variable of body image. Gray's [73] questionnaire consists of 12 statements dealing with one's feelings toward the entire body, examining both positive and negative thoughts concerning one's body. The final score signifies the extent of positive or negative feelings one has towards one's own whole body, how much one accepts or is disappointed with one's own body and appearance. The questionnaire was translated into Hebrew by Palgi [74] as part of his doctoral dissertation, and its internal reliability was then (Cronbach's alfa) $\alpha=0.82$ [75]. In the current study, the internal reliability was high: $\alpha=0.89$.

4) The subjective sense of wellbeing was measured by the Mental Health Inventory (MHI) questionnaire, compiled by Veitand Ware [76] and translated into Hebrew by Florian and Drori [77]. The current study used a shortened version of 10 questions that examined level of personal wellbeing and extent of positive feelings. There were also questions investigating emotional stress and negative feelings. A reliability and viability test of this questionnaire in 1990 yielded a reliability of $\alpha=0.96$. In the current study, the questionnaire yielded a high internal reliability of $\alpha=0.89$ for mothers and even higher for their daughters, $\alpha=0.96$.

5) The connection between mother and daughter was examined by the Relationship with Mother Questionnaire [78]. This questionnaire's 27 items touch upon various aspects of this relationship such as: emotional intimacy, autonomy, communication, and mutual relations. In the current study, this questionnaire was found to have high internal reliability, $\alpha=0.90$ for the mothers and $\alpha=0.94$ for the daughters.

\subsection{Research Procedure}

This research utilized a website module (Qualtrics). The questionnaire was displayed using social networking, including the Facebook platform, and we also approached mothers and teenagers and asked them to display the questionnaire on their personal Facebook page. We also recruited participants through various forums that work or are involved with parents and teenagers, such as schools and community centers.

\section{Results}

Various analyses of the data were performed: paired sample t-tests comparing means of selected variables between mothers and their daughters, Pearson's zero-order correlations between mothers' and daughters' perception of their relationship, and multiple regression analyses to predict the daughters' wellbeing using daughters' and mothers' variables. Two-way interaction analysis was conducted by performing regression analysis and including the interaction term of daughters' body image and mothers' perception of the mother-daughter relationship (centered prior to computation), predicting the daughters' general wellbeing (see Table 1).

Paired sample t-tests comparing means in selected variables between mothers and their daughters showed the following: frequency of physical activity was statistically more significant for daughters than for their mothers; mothers had a higher BMI than their daughters; and the mothers' perception of their daughters' body image was significantly more positive compared to their daughters' perception, $\mathrm{t}(45)=-2.28, \mathrm{p}<0.05$.

Table 1. Differences in selected variables between mothers and their daughters.

\begin{tabular}{|c|c|c|c|c|c|c|}
\hline & \multirow{2}{*}{$\mathrm{T}$} & \multirow{2}{*}{$\mathrm{n}$} & \multicolumn{2}{|c|}{ Daughters } & \multicolumn{2}{|c|}{ Mothers } \\
\hline & & & SD & M & $\mathrm{SD}$ & M \\
\hline Relationships & -0.43 & 46 & 1.15 & 4.24 & 0.86 & 4.19 \\
\hline Physical activity & $-3.60^{* *}$ & 46 & 38.02 & 46.95 & 24.58 & 23.61 \\
\hline BMI & $-4.38^{* * *}$ & 42 & 3.11 & 20.28 & 3.66 & 23.37 \\
\hline General wellbeing & -1.31 & 46 & 1.01 & 3.82 & 0.79 & 4.03 \\
\hline 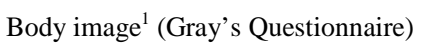 & $-2.28^{*}$ & 46 & 0.77 & 3.21 & 0.62 & 3.45 \\
\hline
\end{tabular}

Note: ${ }^{1}$ Mothers' scores on the body image scale is the perception of their daughter's body image. ${ }^{*} \mathrm{p}<0.05,{ }^{* *} \mathrm{p}<0.01,{ }^{* * *} \mathrm{p}<0.001$. 
Pearson's zero-order correlations revealed positive and strong association between mothers' and daughters' perception of their relationship, $\mathrm{r}(46)=0.68, \mathrm{p}<0.001$. In other words, positive relationship perception made by the mother was directly correspondent to the daughter's perception (and vice versa). It also was observed that daughters' general wellbeing was related to their body image as perceived by their mothers, $r(45)=0.45, p<$ 0.001. Daughters' body image was positively associated with mothers' general wellbeing, $r(46)=0.30, p<0.05$. Finally, daughters' body image, rated separately by mothers and by daughters was significantly positively related, $\mathrm{r}(46)=0.52, \mathrm{p}<0.001$ (see Table 2 below).

Multiple regression analysis that predicted daughters' wellbeing using daughters' and mothers' variables yielded a significant overall regression model, $F(4,37)=29.57, \mathrm{p}<0.001, \mathrm{R}^{2}=0.76, \mathrm{R}^{2} \mathrm{Adj}=0.74$. Daughters' BMI and daughters' body image perception were the only variables that contributed significantly to daughters' general wellbeing, together accounting for more than $75 \%$ of the variance in general wellbeing. In step 2 , the addition of mothers' variables did not contribute to the interpretation of daughter's general wellbeing, as none of these variables predicted general wellbeing. Daughters' BMI and body image once again contributed significantly to wellbeing (see Table 3 below).

\section{Body Image and Mother-Daughter Relationship Interaction}

Two-way interaction analysis was conducted by performing regression analysis and including the interaction term of body image and daughter's perception of the relationship (centered prior to computation), predicting daughter's general wellbeing. The regression model was found statistically significant, $F(3,42)=47.14, p<$

Table 2. Zero-order correlations between mothers’ \& daughters’ variables.

\begin{tabular}{ccccccc}
\hline & & \multicolumn{3}{c}{ Daughters } \\
\hline & $\begin{array}{c}\text { Body image }^{1} \\
\text { (Gray's Questionnaire) }^{*}\end{array}$ & General wellbeing & BMI & Physical activity & Relationships \\
Relationships & 0.05 & 0.06 & -0.13 & -0.07 & $0.68^{* * *}$ \\
Physical activity & 0.10 & 0.06 & -0.01 & 0.07 & -0.01 \\
BMI & -0.14 & -0.26 & 0.09 & 0.04 & -0.15 \\
Mothers & $0.30^{*}$ & 0.27 & 0.01 & -0.05 & -0.01 \\
\hline $\begin{array}{c}\text { General wellbeing } \\
\text { Body image }\end{array}$ & $0.52^{* *}$ & $0.45^{* *}$ & -0.16 & 0.07 & 0.02 \\
\hline
\end{tabular}

Table 3. Summary of multiple regression predicting daughters' general wellbeing $(\mathrm{N}=46)$.

\begin{tabular}{|c|c|c|c|c|c|c|}
\hline \multirow[b]{2}{*}{ Variable } & \multicolumn{3}{|c|}{ Step 2} & \multicolumn{3}{|c|}{ Step 1} \\
\hline & $\mathrm{B}$ & SE B & $\mathrm{B}$ & $\mathrm{B}$ & SE B & B \\
\hline Daughter's relationship perception & 0.22 & 0.13 & 0.19 & 0.10 & 0.08 & 0.08 \\
\hline Daughter's BMI & $0.21^{*}$ & 0.03 & 0.07 & $0.19^{*}$ & 0.03 & 0.06 \\
\hline Daughter’s physical activity & 0.06 & 0.00 & 0.00 & 0.05 & 0.00 & 0.00 \\
\hline Daughter’s body image & $0.73^{* * *}$ & 0.16 & 0.97 & $0.85^{*}$ & 0.13 & 1.12 \\
\hline Mother's relationship perception & -0.13 & 0.14 & -0.15 & & & \\
\hline Mother's BMI & -0.12 & 0.02 & -0.03 & & & \\
\hline Mother’s physical activity & -0.03 & 0.00 & 0.00 & & & \\
\hline Mother's body image & 0.13 & 0.20 & 0.22 & & & \\
\hline Mother's general wellbeing & -0.03 & 0.13 & -0.04 & & & \\
\hline $\mathrm{R}^{2}$ & & 0.74 & & & 0.74 & \\
\hline $\mathrm{F}$ for change in $\mathrm{R}^{2}$ & & 1.11 & & & $29.57^{* * *}$ & \\
\hline
\end{tabular}

Note: ${ }^{*} \mathrm{p}<0.05 .{ }^{* *} \mathrm{p}<0.01,{ }^{* * *} \mathrm{p}<0.001$. 
$0.001, \mathrm{R}^{2}$ Adj $=0.75$. Relations perception moderated the impact of body image on general wellbeing among daughters; as in the event of low body image, a strong mother-daughter relationship yielded a higher level of general wellbeing. In the event of a higher-level body image, girls with a weak mother-daughter relationship had a similar level of wellbeing as girls with a strong mother-daughter relationship (see Figure 1).

Two-way interaction analysis was conducted by performing regression analysis and including the interaction term of daughter's body image and mother's perception of the relationship (centered prior to computation), predicting daughter's general wellbeing. The regression model was found statistically significant, $F(3,42)=44.58$, $\mathrm{p}<0.001, \mathrm{R}^{2} \mathrm{Adj}=0.74$. When the daughter had a high level of body image, there was a trend toward the mother's relationship perception being positively associated with the daughter's wellbeing (95\% CI: -0.55 0.05); however, when the daughter's body image was low, this association became negative (95\% CI: -0.01 0.66). In other words, among daughters with a high-level body image, strong mother-daughter relations (as perceived by the mother) were associated with daughter's greater wellbeing, while among daughters with low body image stronger mother-daughter relations (as perceived by the mother) were associated with reduced daughter's wellbeing (see Figure 2).

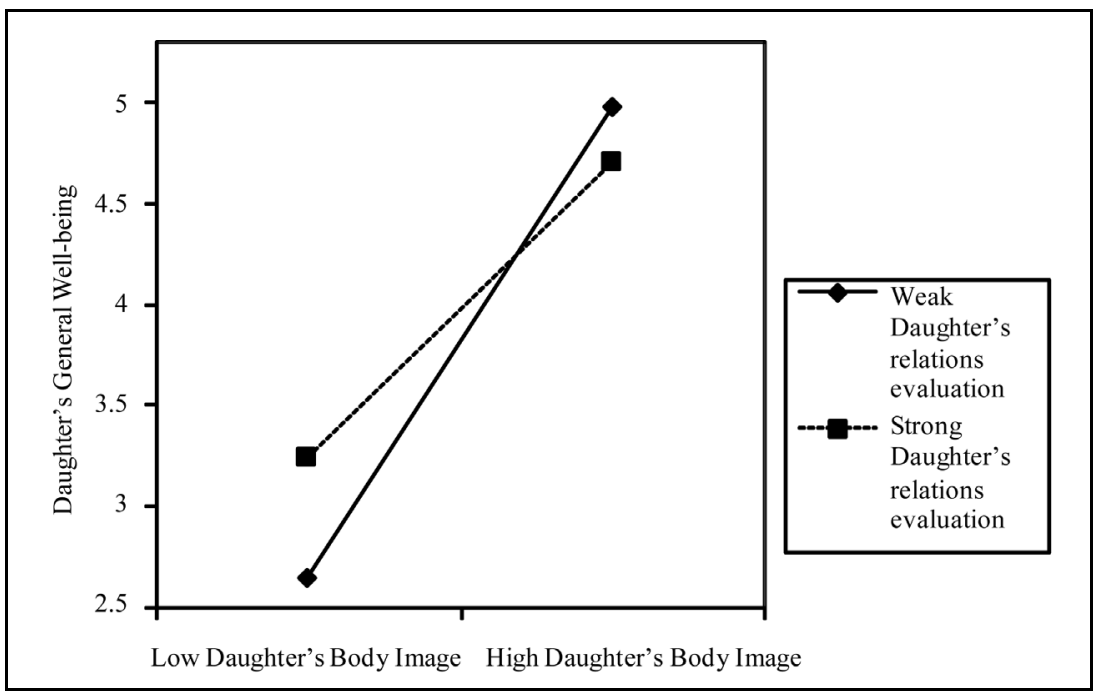

Figure 1. Body image and mother-daughter relationship interaction (daughter's perception).

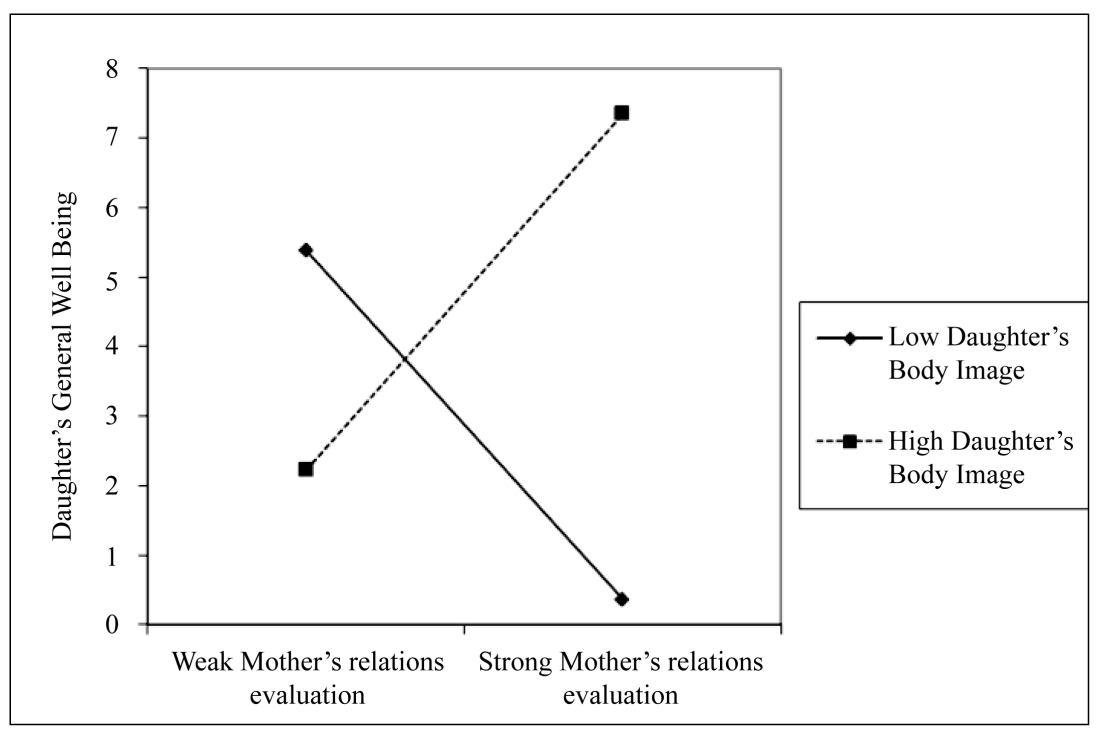

Figure 2. Body image and mother-daughter relationship interaction (mother's perception of her daughter's perception). 


\section{Discussion}

This research assessed and evaluated the effect of the adolescent daughter's body image (independent variable) and her relationship (independent variable) with her mother on the daughter's perception of her wellbeing (dependent variable). Moreover, the research predicted the contribution of the daughter's perception of her relationship with her mother to her wellbeing and the connection between her body image perception and her wellbeing.

The inter-generational approach suggests that the mother's body image will be transferred to her daughter through the relationship between them [37]. However, here, the current study found significant differences between the daughter's body image perception and the mother's perception of her daughter's body image. The mother's perception of the way in which her daughter assesses her own body image was more positive than the daughter's actual assessment of herself.

Examination of Body Mass Index (BMI) and physical activity involvement indicated differences between mothers and daughters. The daughters' BMI values were lower than those of the mothers, probably due to their younger age and greater participation in physical activity. These findings were compatible with those of previous studies that investigated the typical characteristics of adolescence [70]. This also may be why the mothers had a more positive perception of their daughters' BMI levels than their daughters.

Upon examination of these variables, we found a positive connection between the way in which mothers and daughters evaluated the quality of their relationship, which lies in the mutual bond between them. This positive connection may be explained by Bowlby's attachment theory [40], that the perception of the quality of the relationship that develops by adolescence is based on the early parent-child experiences.

Another explanation for the positive connection in perception of the quality of their relationship is Charles Cooley's “looking-glass self' theory” [79]. Cooley notes that a person's self develops in life's initial groups, with the family serving as the most significant primary group. According to Cooley's theory [46], the self develops through a three-step social process: the first is how we think others perceive our behavior, the second is how we think others judge our behavior, and the third is how we assess our own behavior in light of others' reactions to it. Hence, people evaluate themselves according to how they conceive of others' feelings toward their behavior and appearance [79]. The mother-daughter relationship has a strong influence over how the adolescent girl perceives her body image [8]. In fact, mothers can directly or indirectly affect behaviors in many areas of their children's life, whether they be eating habits, attitudes toward themselves, or certainly, body image [46].

Cooley et al. [46] found in their study that the extent to which a mother appreciates her daughter's body image perception correlates to the daughter's subjective wellbeing. This can be explained by Fischer [44], who claimed that the mutual dependence and emotional connection between a mother and daughter is more significant than any other relationship. Moreover, it is crucial to the daughter's self-definition and her sense of satisfaction with her own life [45]. The same finding here may be related to the previous one in this study in which the mother had a more positive perception of her daughter's body weight than did the daughter herself. This study also revealed a strong positive correlation between the way in which the daughter perceives her own body and the way in which the mother perceives her daughter's body image.

Moreover, the factors most likely to predict what will contribute to increased wellbeing among adolescent girls were investigated. In the first regression analysis model for predicting adolescent girls' subjective sense of wellbeing, it was found that body image perception is the most significant predictor. BMI was also a predictor; however, physical activity was not a contributing factor. The BMI measure serves as a representation of the girl's outward appearance, an internal point of reference that helps her and those around her to form a view and perception of herself [80].

Based on the influence of these variables, we chose to expand examination of the effect of relationship perception by comparing the mother's and daughter's perception of the quality of their relationship. Inspection of these two points-of-view yielded contradicting results, relating to adolescent girls' high-level and low-level body image perception. If only the mother perceives her relationship with her daughter as being a good one, then the daughter's negative body image will be the deciding factor, and the daughter will have a low sense of wellbeing. In other words, a good relationship with her mother as perceived by the daughter increases the daughter's wellbeing even when she feels negatively about her body, because her connection with her mother serves as a support column for all that pertains to the emotional development that affects a sense of wellbeing. This finding is in accordance with earlier research that noted that a sense of security with an attachment figure seems to instill 
a positive self-image in which a person feels good about him/herself in a variety of adjustment areas including body image, vocational/educational goals, and social relationships [42] [43]. For girls who have a positive body image but a poor mother-daughter relationship, the latter does not seem to negatively influence her feeling of wellbeing.

It seems that in instances of this kind, the contribution of the environment is central. On this matter, Diener and colleagues suggest that people who are highly satisfied with their bodies and external appearance value themselves as more attractive and feel that others consider them attractive, all of which raise their subjective sense of wellbeing [80].

The model teaches us that the daughter's BMI, body image and perception of the mother-daughter relationship are the significant factors in the daughter's sense of wellbeing, when measuring the daughter's life satisfaction.

\section{Conclusions}

This research study explored the relationship between mothers and their adolescent daughters. The adolescent years, characterized by emotional upheaval and extreme hormonal and physiological changes, create numerous situations of stress and conflict between adolescents and their parents. Mothers often feel rejected and alienated by their daughters who wish to shape their own identity and strive for a sense of autonomy. The current research findings emphasize the importance of the mother-daughter relationship and the mother's emotional support in forging a positive body image. They also show that the girl's perception of her body image significantly affects her sense of wellbeing. Furthermore, the adolescent girl's positive perception of her relationship with her mother is an important factor in her positive body image and high-level sense of wellbeing. As we learned from the study, a good relationship with her mother increased the daughter's wellbeing even when she felt negatively about her body.

This study shows the unique contribution of body image perception on the subjective sense of wellbeing among adolescent girls, emphasizing the importance of paying attention to the consequences of physiological changes and emotional upheaval at this age. Both the family and professionals should be in touch with the adolescent girl as she undergoes this stressful period, in order to prevent potentially damaging negative developments.

In addition to the programs integrated into the educational system (sex education, risky and unsafe behaviors), tools beyond the objective measurements (BMI as figured by height and weight) can be developed that measure the girl's perception of her body image and her relationship with her mother. Early identification of adolescent girls whose negative body image contradicts the objective data may prevent a worsening situation of the adolescents. Moreover, increasing the mothers' awareness of the importance of building a supportive relationship with her daughter may also prevent negativity.

The uniqueness of this study lies in its structure, i.e. the use of the dyadic mother-daughter relationship. The analyses were pursued from several points of view: how the daughter perceived herself; how she perceived her mother; how the mother perceived her daughter; and how she perceived their relationship. The multi-dimensional analysis indicates the significance of the mother-daughter relationship, especially the daughter's perception of this relationship, and particularly during adolescence. The study was conducted on 46 dyads, though in the future this may be done again on a larger population sample, with subdivisions by age, in order to learn more closely the characteristics of each developmental stage in adolescence.

\section{References}

[1] Te’omim, S. (2006) Mar’a mar'a she’al ha'kir, mi ha-yafa be-chol hair? (Mirror, Mirror on the Wall, Who Is the Prettiest of Them All?) http://lib.cet.ac.il/Pages/item.asp?item=13258\&kwd=7424

[2] Van Den Berg, P., Keery, H., Eisenberg, M. and Neumark-Sztainer, D. (2010) Maternal and Adolescent Report of Mothers’ Weight-Related Concerns and Behaviors: Longitudinal Associations with Adolescent Body Dissatisfaction and Weight Control Practices. Journal of Pediatric Psychology, 35, 1093-1102. http://dx.doi.org/10.1093/jpepsy/jsq042

[3] National Association of Social Workers (2001) Adolescent Girls and Body Image. Practice Update from the National Association of Social Workers, 2. http://www.naswdc.org/practice/adolescent_health/ah0204.asp

[4] Polivy, J., Garner, D.M. and Garfinkel, P.E. (1986) Causes and Consequences of the Current Preference for Thin Fe- 
male Physics. In: Herman, C.P., Zanna, M.P. and Higgins, E.T., Eds., Physical Appearance, Stigma, and Social Behavior: Proceedings of the Third Ontario Symposium in Personality and Social Psychology, N.S. Erlbaum Associates, Hillsdale, 89-112.

[5] Bearman, S.K., Presnell, S., Martinez, E. and Stice, E. (2006) The Skinny on Body Dissatisfaction: A Longitudinal Study of Adolescent Girls and Boys. Journal of Youth and Adolescence, 35, 229-241. http://dx.doi.org/10.1007/s10964-005-9010-9

[6] Flum, H. (1995) Mitbagrim be-Yisrael: Hebaytimishi'im, mishpahti'imve-hevruti'im. (Adolescents in Israel: Personal, Family and Social Aspects.) Even Yehuda, Reches, 123-145.

[7] Moss, R.A. (1988) Teoriyot al gilhitbagrut. (Theories about Adolescence.) Sifriat Ha Poalim, Tel Aviv.

[8] Asher, J.M. (1992) Ha’psichologiashelgufha'isha. (The Psychology of the Female Body.) Ach Publishers, Kiryat Bialik.

[9] Blodgett Salafia, E.H., Gondoli, D.M., Corning, A.F., McEnery, A.M. and Grundy, A.M. (2007) Psychological Distress as a Mediator of the Relation between Perceived Maternal Parenting and Normative Maladaptive Eating among Adolescent Girls. Journal of Counseling Psychology, 54, 434-446. http://dx.doi.org/10.1037/0022-0167.54.4.434

[10] Ogden, J. and Steward, J. (2000) The Role of the Mother-Daughter Relationship in Explaining Weight Concern. International Journal of Eating Disorders, 28, 78-83. http://dx.doi.org/10.1002/(SICI)1098-108X(200007)28:1<78::AID-EAT9>3.0.CO;2-N

[11] Capon-Sohezki, P. (2007) Ha’arachaatzmit, dimuiguf, perfectsionismve-hafraotachilaetzelne’arotmitbagrotha’lomdot ballet. (Self Assessment, Body Image, Perfectionism, and Eating Disorders among Adolescent Females Learning Ballet.) Master's Thesis, Haifa University, Haifa.

[12] Fein, H. (2004) Maholve-tnuayotzeretb’avodakvutzatit. (Group Dance and Creative Movement.) Re’emim Offset Publishers, Ltd., Holon.

[13] Kurtz, L. (2010) Dimuiatzmive-dimuiguf. (Self Image and Body Image.) Israeli Oncological Nursing Newsletter, 19.

[14] Tamir, T. (2011) Nashim le-gufan. (Women on Their Bodies.) Modan, Ben Shemen.

[15] Cash, T.F. and Smolak, L. (2011) Understanding Body Images: Historical and Contemporary Perspectives. In: Cash, T.F. and Smolak, L., Eds., Body Image: A Handbook of Science, Practice, and Prevention, Guilford Press, New York, 3-11.

[16] Fallon, A. (1990) Culture in the Mirror: Socio-Cultural Determinants of Body Image. In: Cash, T.F. and Pruzinstky, T., Eds., Body Images: Development, Deviance, and Change, Guilford Press, New York, 80-109.

[17] Thompson, J.K. and Stice, E. (2001) Thin-Ideal Internalization: Mounting Evidence for a Development and Implementation of the Body Logic Program for Adolescents: A Two-Stage Prevention Program for Eating Disorder. Cognitive and Behavioral Practice, 8, 248-259.

[18] Becker, A. (1995) Kishreigomlinbeindigmeiyachasibein-ishi'imshelimahotl’veindfuseiha’tzmidutshelyaldeihem. (Mutuality between Examples of Mothers' Interpersonal Relationships and Their Children’s Attachment Patterns.) Tel Aviv University Press, Tel Aviv.

[19] Hurd Clarke, L. and Griffin, M. (2007) Becoming and Being Gendered through the Body: Older Women, Their Mothers and Body Image. Ageing and Society, 27, 701-718. http://dx.doi.org/10.1017/S0144686X0700623X

[20] Liechty, T. (2009) Body Image and Leisure among Older Women. Doctoral Dissertation, The Pennsylvania State University, Pennsylvania.

[21] Liechty, T. and Yarnal, C. (2010) Older Women’s Body Image: A Life-Course Perspective. Ageing \& Society, 30, 1197-1218. http://dx.doi.org/10.1017/S0144686X10000346

[22] Manos, D., Sebastián, J., Bueno, M.J., Mateos, N. and De la Torre, A. (2005) Body Image in Relation to Self-Esteem in a Simple of Spanish Women with Early-Stage Breast Cancer. Psicooncología, 2, 103-116.

[23] Liu, C., Ang, R.P. and Lwin, M.O. (2013) Cognitive, Personality, and Social Factors Associated with Adolescents' Online Personal Information Disclosure. Journal of Adolescence, 36, 629-638.

http://dx.doi.org/10.1016/j.adolescence.2013.03.016

[24] Erikson, E.H. (1950) Childhood and Society. Norton Company, New York, 403-426.

[25] Greenberg, L. and Ben Bessat, V. (2009) Tfisatdimuiatzmi, dimuiguf, hergeleipe'ilutgufanitve-tzunab’kerevmitbagrot. (Perception of Self-Esteem, Body Image, and Exercise and Nutrition Habits among Adolescent Girls.) B'Tnua (In Movement), 9, 217-236.

[26] Coccia, C., Darling, C., Rehm, M., Cui, M. and Sathe, S. (2012) Adolescent Health, Stress, and Life Satisfaction: The Paradox of Indulgent Parenting. Stress and Health, 28, 211-221. http://dx.doi.org/10.1002/smi.1426

[27] Barker, E.T. and Galambos, N.L. (2003) Body Dissatisfaction of Adolescent Girls and Boys: Risk and Resource Fac- 
tors. The Journal of Early Adolescence, 23, 141-165. http://dx.doi.org/10.1177/0272431603023002002

[28] Presnell, K., Bearman, S. and Stice, E. (2004) Risk Factors for Body Dissatisfaction in Adolescent Boys and Girls: A Prospective Study. International Journal of Eating Disorders, 36, 389-401. http://dx.doi.org/10.1002/eat.20045

[29] Rosenblum, G.D. and Lewis, M. (1999) The Relations among Body Image, Physical Attractiveness, and Body Mass in Adolescence. Child Development, 70, 50-64. http://dx.doi.org/10.1111/1467-8624.00005

[30] Field, A.E., Coakley, E.H., Must, A., Spadano, J., Laird, N., Dietz, W., Rimm, E. and Colditz, G. (2001) Impact of Overweight on the Risk of Developing Common Chronic Diseases during a 10-Year Period. JAMA Internal Medicine, 161, 1581-1586. http://dx.doi.org/10.1001/archinte.161.13.1581

[31] Carroll, P., Tiggemann, M. and Wade, T. (1999) The Role of Body Dissatisfaction and Bingeing in the Self-Esteem of Women with Type II Diabetes. Journal of Behavioral Medicine, 22, 59-74. http://dx.doi.org/10.1023/A:1018799618864

[32] Cash, T.F. and Henry, P.E. (1995) Women’s Body Images: The Results of a National Survey in the U.S.A. Sex Roles, 33, 19-28. http://dx.doi.org/10.1007/BF01547933

[33] Frisén, A., Lunde, C. and Hwang, P. (2009) Peer Victimisation and Its Relationships with Perceptions of Body Composition. Educational Studies, 35, 337-348. http://dx.doi.org/10.1080/03055690802648200

[34] Knauss, C., Paxton, S.J. and Alsaker, F.D. (2007) Relationships amongst Body Dissatisfaction, Internalisation of the Media Body Ideal and Perceived Pressure from Media in Adolescent Girls and Boys. Body Image, 4, 353-360. http://dx.doi.org/10.1016/j.bodyim.2007.06.007

[35] Tiggemann, M. and Lynch, J.E. (2001) Body Image across the Life Span in Adult Women: The Role of Self-Objectification. Developmental Psychology, 37, 243-253. http://dx.doi.org/10.1037/0012-1649.37.2.243

[36] Kenemor, E. and Spira, M. (1996) Mothers and Their Adolescent Daughters: Transitions and Transformations. Child and Adolescent Social Work Journal, 13, 225-240. http://dx.doi.org/10.1007/BF01875789

[37] Onayli, S. (2010) The Relations between Mother-Daughter Relationship and Daughter’s Well-Being. Master's Thesis, The Graduate School of Social Sciences of Middle East Technical University, Ankara.

[38] O’Donnell, W. (1976) Adolescent Self-Esteem Related to Feelings towards Parents and Friends. Journal of Youth and Adolescence, 5, 179-185. http://dx.doi.org/10.1007/BF01537492

[39] Youniss, J. (1980) Parents and Peers in Social Development. The University of Chicago Press, Chicago.

[40] Bowlby, J. (1988) A Secure Base: Parent-Child Attachment and Healthy Human Development. Basic Books, New York.

[41] Greenberg, M.T., Siegel, J.M. and Leitch, C.J. (1983) The Nature and Importance of Attachment Relationships to Parents and Peers during Adolescence. Journal of Youth and Adolescence, 12, 373-386. http://dx.doi.org/10.1007/BF02088721

[42] Kenny, M.E., Griffiths, J. and Grossman, J. (2005) Self-Image and Parental Attachment among Late Adolescents in Belize. Journal of Adolescence, 28, 649-664. http://dx.doi.org/10.1016/j.adolescence.2005.08.009

[43] Offer, D., Ostrov, E., Howard, K.J. and Dolan, S. (1992) Offer Self-Image Questionnaire, Revised. Western Psychological Services, Los Angeles.

[44] Fisher, S. (1990) The Evolution of Psychological Concept about the Body. In: Cash, T.F. and Pruzinstky, T., Eds., Body Images: Development, Deviance, and Change, Guilford Press, New York.

[45] La Sorsa, V.A. and Fodor, I.G. (1990) Adolescent Daughter/Mid-Life Mother Dyad: A New Look at Separation and Self-Definition. Psychology of Women Quarterly, 14, 593-606. http://dx.doi.org/10.1111/j.1471-6402.1990.tb00233.x

[46] Cooley, E., Toray, T., Wang, M.C. and Valdez, N.N. (2008) Maternal Effects on Daughters’ Eating Pathology and Body Image. Eating Behaviors, 9, 52-61. http://dx.doi.org/10.1016/j.eatbeh.2007.03.001

[47] Jaffe, K. and Worobey, J. (2006) Mothers' Attitudes toward Fat, Weight and Dieting in Themselves and Their Children. Body Image, 3, 113-120. http://dx.doi.org/10.1016/j.bodyim.2006.03.003

[48] Steiger, H., Stotland, S., Ghadirian, A.M. and Whitehead, V. (1994) Controlled Study of Eating Concerns and Psychopathological Traits in Relative of Eating Disordered Probands: Do Familial Traits Exist? International Journal of Eating Disorders, 18, 107-118. http://dx.doi.org/10.1002/1098-108X(199509)18:2<107::AID-EAT2260180202>3.0.CO;2-1

[49] Hall, A. and Brown, L.B. (1982) A Comparison of the Attitudes of Young Anorexia Nervosa Patients and Non Patients with Those of Their Mothers. British Journal of Medical Psychology, 56, 39-48. http://dx.doi.org/10.1111/j.2044-8341.1983.tb01530.x

[50] Attie, I. and Brooks-Gunn, J. (1989) Development of Eating Problems in Adolescent Girls: A Longitudinal Study. Developmental Psychology, 25, 70-79. http://dx.doi.org/10.1037/0012-1649.25.1.70 
[51] Holzgraefe, S. (2003) Side by Side: Reinventing Mother/Daughter Relationships. Master Thesis, University of North Texas, Denton.

[52] Blyth, D.A., Hill, J.P. and Thiel, K.S. (1982) Early Adolescents' Significant Others: Grade and Gender Differences in Perceived Relationships with Familial and Nonfamilial Adults and Young People. Journal of Youth and Adolescence, 11, 425-450. http://dx.doi.org/10.1007/BF01538805

[53] Cauce, A.M., Felner, R.D. and Primavera, J. (1982) Social Support in High Risk Adolescents: Structural Components and Adaptive Impact. American Journal of Community Psychology, 10, 417-428. http://dx.doi.org/10.1007/BF00893980

[54] Raja, S., McGee, R. and Stanton, W.R. (1992) Perceived Attachments to Parents and Peers and Psychological WellBeing in Adolescence. Journal of Youth and Adolescence, 21, 471-485. http://dx.doi.org/10.1007/BF01537898

[55] Youniss, J. and Smollar, J. (1985) Adolescent Relations with Mothers, Fathers and Friends. University of Chicago Press, Chicago. http://lib.cet.ac.il/Pages/item.asp?item=13258\&kwd=742

[56] Cassidy, J. (1988) Child-Mother Attachment and the Self in Six-Year-Olds. Child Development, 59, 121-134. http://dx.doi.org/10.2307/1130394

[57] Sroufe, L.A., Fox, N.E. and Pancake, V.R. (1983) Attachment and Dependency in Developmental Perspective. Child Development, 54, 1615-1627. http://dx.doi.org/10.2307/1129825

[58] Armsden, G.C. and Greenberg, M.T. (1987) The Inventory of Parent and Peer Attachment: Individual Differences and Their Relationship to Psychological Well-Being in Adolescence. Journal of Youth and Adolescence, 16, 427-454. http://dx.doi.org/10.1007/BF02202939

[59] Diener, E. (2000) Subjective Well-Being: The Science of Happiness, and a Proposal for a National Index. American Psychologist, 55, 34-43. http://dx.doi.org/10.1037/0003-066X.55.1.34

[60] Diener, E. (1984) Subjective Well-Being. Psychological Bulletin, 95, 542-575. http://dx.doi.org/10.1037/0033-2909.95.3.542

[61] Andrews, F.M. and Robinson, J.P. (1991) Measures of Subjective Well-Being. Academic Press, San Diego.

[62] Diener, E., Lucas, R.E. and Oishi, S. (2002) Subjective Well-Being, the Science of Happiness and Life Satisfaction. In: Snyder, C.R. and Lopez, S.J., Eds., Handbook of Positive Psychology, Oxford University Press, Oxford, 63-73.

[63] Samman, E. (2007) Psychological and Subjective Well-Being: A Proposal for Internationally Comparable Indicators. Oxford Development Studies, 35, 459-486. http://dx.doi.org/10.1080/13600810701701939

[64] Rejeski, W. and Mihalko, S. (2001) Physical Activity and Quality of Life in Older Adults. Journals of Gerontology: Series A, 56, 23-35. http://dx.doi.org/10.1093/gerona/56.suppl_2.23

[65] Diener, E. (1994) Measuring Subjective Well Being: Progress and Opportunities. Social Indicators Research, 28, 3589.

[66] Diener, E. and Diener, C. (1996) Most People Are Happy. Psychological Science, 7, 181-185. http://dx.doi.org/10.1111/j.1467-9280.1996.tb00354.x

[67] Suldo, S.M., Huebner, E.S., Friedrich, A. and Gilman, R. (2009) Life Satisfaction. In: Gilman, R., Huebner, E.S. and Furlong, M., Eds., Handbook of Positive Psychology in the Schools, Routledge Publications, New York, 27-36.

[68] Fattore, T., Mason, J. and Watson, E. (2009) When Children Are Asked about Well-Being: Towards a Framework for Guiding Policy. Child Indicators Research, 2, 57-77. http://dx.doi.org/10.1007/s12187-008-9025-3

[69] Walter, O. and Ben Zvi, L. (2011) Ha'rikudbe’maagalu’bahalalha’hofshive-hashpa'atam al visutrigshi, shlitaatzmit, ve-thushatbitahonba'gilha'rach. (Circle Dance and Free Dance and Their Influence on Self-Regulation, Self-Control and a Sense of Security in Toddlers.) TipulOmanuti (Academic Journal of Creative Arts Therapies), 1, 12-22.

[70] Godin, G. and Shepard, R.J. (1985) A Simple Method to Assess Exercise Behavior in the Community. Canadian Journal of Applied Sport Sciences, 10, 141-146.

[71] Pietrobelli, A., Faith, M.S., Allison, D., Gallagher, D., Chiumello, G. and Heymsfield, S. (1998) Body Mass Index as a Measure of Adiposity among Children and Adolescents: A Validation Study. The Journal of Pediatrics, 132, $204-210$. http://dx.doi.org/10.1016/S0022-3476(98)70433-0

[72] National Heart Foundation in Association with the Faculty of Public Health and Department of Health (2007) Lightening the Load: Tackling Overweight and Obesity: A Toolkit for Developing Local Strategies to Tackle Overweight and Obesity in Children and Adults. Department of Health, London. http://www.dh.gov.uk/en/Publicationsandstatistics/Publications/PublicationsPolicyandGuidance/dH_073936

[73] Gray, S.H. (1977) Social Aspects of Body Image: Perception of Normalcy of Weight and Affect of College Undergraduates. Perceptual and Motor Skills, 45, 1035-1040. http://dx.doi.org/10.2466/pms.1977.45.3f.1035

[74] Palgi, Y. (2008) The Relations of Extreme Life Events and Subjective Well-Being with Functioning and Mortality at 
Old-Old Age: A Longitudinal Research. Ph.D. Dissertation, Tel Aviv University, Tel Aviv.

[75] Besser, A., Amir, M. and Barkan, S. (2004) Who Signs an Organ Transplant Donor Card? A Study of Personality and Individual Differences in a Sample of Israeli University Students. Personality and Individual Differences, 36, 17091723. http://dx.doi.org/10.1016/j.paid.2003.07.012

[76] Veit, C.T. and Ware, J.E. (1983) The Structure of Psychological Distress and Well-Being in General Populations. Journal of Consulting and Clinical Psychology, 51, 730-742. http://dx.doi.org/10.1037/0022-006X.51.5.730

[77] Florian, V. and Drory, Y. (1990) Tchunotnormativiyot (MHI) she'elonha’briutha'nafshit. (Mental Health Inventory (MHI) Questionnaire: Normative Characteristics and Data in the Israeli Population.) Psychology B, 26-35.

[78] Mayseless, O. and Hai, I. (1998) Leaving Home Transition in Israel: Changes in Parent-Adolescents Relationships and Adolescents’ Adaptation to Military Service. International Journal of Behavioral Development, 22, 589-609. http://dx.doi.org/10.1080/016502598384289

[79] Neve, N., Elad, R. and Ran, O. (2003) Sociologia be-maagaleiha’hevra-hibrut. (Sociology in Social Circles-Socialization.) Reches, Tel Aviv.

[80] Diener, E., Wolsic, B. and Fujita, F. (1995) Physical Attractiveness and Subjective Well-Being. Journal of Personality and Social Psychology, 69, 120-129. http://dx.doi.org/10.1037/0022-3514.69.1.120 